\title{
O papel pedagógico dos jornalistas no Rio de Janeiro oitocentista*
}

\author{
The pedagogical role of journalists in Rio de Janeiro of the nineteenth century
}

\author{
Vinicius Cranek Gagliardo \\ Doutorando em História na Universidade Estadual Paulista \\ Júlio de Mesquita Filho, campus de Franca \\ viniciusgagliardo@yahoo.com.br
}

Resumo: Durante o século XIX, a imprensa brasileira caracterizou-se pela estreita vinculação com a instrução da população. Até 1841 , a instrução associou-se ao esclarecimento político e a liberdade e prosperidade dos povos. O jornalista deveria defender suas ideias e posicionamentos sobre os assuntos políticos, procurando influenciar os leitores/ouvintes. Neste contexto, a imprensa passou a ser vista como instrumento de difusão particularmente de ideias políticas. Este artigo tem por objetivo explicitar o papel pedagógico de esclarecedor das ideias políticas conferido aos jornalistas no Rio de Janeiro nas décadas de 1820 e 1830, bem como apontar para a consolidação, por meio da imprensa literária a partir dos anos 1840, da figura do intelectual como mentor da sociedade.

Palavras Chaves: Imprensa, Pedagogia, Intelectual.

\begin{abstract}
During the nineteenth century, the Brazilian press was characterized by close connection to the instruction of the population. Until 1841, instruction was associated with political enlightenment and to liberty and prosperity of the people. The journalist should defend his ideas and positions on political issues, seeking to influence the readers/listeners. In this context, the press came to be seen as a dissemination tool, particularly of political ideas. This article aims to describe the pedagogical role of clarification of political ideas conferred on journalists in Rio de Janeiro in the 1820s and 1830s, as well as to point out the consolidation, through the literary press from the 1840 s, of the figure of the intellectual as mentor to the society.
\end{abstract}

Keywords: Press, Pedagogy; Intellectual.

\footnotetext{
* Este artigo é fruto da pesquisa de doutorado em História que integra o Projeto Temático "Escritos sobre os novos mundos: uma história da construção de valores morais em língua portuguesa", ambos financiados pela FAPESP.
} 
Em 13 de maio de 1808, pouco tempo após a chegada de D. João e sua corte ao Brasil, o príncipe regente põe fim ao longo período de proibição de funcionamento de tipografias na então mais importante colônia do Império português. ${ }^{1}$ Até a data da fundação da Impressão Régia, o governo metropolitano coibiu o estabelecimento da imprensa no Brasil, fazendo da circulação da palavra impressa um crime contra a coroa (BAHIA, 2009: 18). Apesar de inicialmente marcada pela necessidade administrativa de manutenção da nova sede do governo português, uma vez que a própria burocracia demandava a publicação de "toda a legislação e papéis diplomáticos", a criação de uma tipografia no Rio de Janeiro foi também o ponto de partida para que, com a publicação de "todas e quaisquer outras obras", a imprensa pudesse se desenvolver no Brasil (COLEÇÃO..., 1891: 29-30).

A criação da Impressão Régia constitui, nesse sentido, um dos marcos da abertura cultural do Brasil para o mundo: se, inicialmente, foi instituída como tipografia oficial e detentora do monopólio de publicação das letras impressas, tornou-se, ao mesmo tempo, a primeira editora brasileira, ao publicar inúmeras outras obras de diversos campos do conhecimento. ${ }^{2}$ Com isso, os laços entre as culturas do Brasil e da Europa se estreitaram, acentuando o desenvolvimento cultural brasileiro (MINDLIN, 2010: 20). Ao imprimir títulos de grande valor para o início da vida editorial brasileira, ultrapassando, de certo modo, os limites iniciais de suas obrigações e deveres oficiais (MARTINS, 1957: 349350), a tipografia régia contribuiu de maneira significativa para o progresso dos espíritos ${ }^{3}$ durante o século XIX, possibilitando ao Brasil figurar não apenas como consumidor de livros, jornais e demais papéis impressos que chegavam aos seus portos, como acontecia até então. A partir daí, passou a ocupar o lugar de produtor desses suportes de construção e divulgação dos saberes (OLIVEIRA, 2011: 56).

Antes de 1808, entretanto, as poucas tentativas de se criarem casas tipográficas no Brasil esbarraram na intransigência das autoridades portuguesas (LUSTOSA, 2004:7). Até a chegada de D. João, as letras impressas permaneceram proibidas: de um lado, não

\footnotetext{
${ }^{1}$ José Marques de Melo, em Sociologia da imprensa brasileira, defende ideia contraria à afirmação de que as tipografias eram proibidas na América portuguesa. $\mathrm{O}$ autor destaca que "não existiu uma legislação expressamente restritiva à instalação de tipografias no Brasil". Ainda segundo o autor, "na realidade, o governo português não chegou a expedir disposições legais que vedassem taxativamente a instalação e funcionamento de tipografias no Brasil" (MELO apud BRAGANÇA, 2005: 45).

${ }^{2}$ Entre 1808 e 1822, a Impressão Régia teria publicado, segundo Alfredo do Valle Cabral, 1.251 títulos (CABRAL, 1881). Já Ana Maria de Almeida Camargo e Rubens Borba de Moraes teriam identificado a impressão de 1.428 títulos. Cf. CAMARGO; MORAES, 1993.

${ }^{3}$ Para o uso do conceito no período ver, por exemplo, CORREIO MERCANTIL (1863: 2).
} 
se podia imprimir qualquer papel, de outro, o governo português procurava conter a importação dos impressos que chegavam aos portos brasileiros, o que resultava em um controle sobre a circulação interna de livros na Colônia, que poderiam ou não ser liberados na Alfândega (ALGRANTI, 2004: 138). Tal controle era motivado pelo fato de Estado e Igreja atribuírem aos impressos o status de fontes de desordem, de questionamentos e, em última instância, de quebra dos laços coloniais (VILLALTA, 1997: 347). No entanto, se na América portuguesa os impressos e as tipografias eram proibidos, isso não impediu a existência de oficinas clandestinas - ainda que de duração efêmera - produzissem e colocassem em circulação impressos e manuscritos responsáveis por disseminar notícias, ideias e opiniões (BARBOSA, 2010: 20). Também não evitou que jornais produzidos na Europa fossem recebidos no Brasil, por meio de contrabando realizado em seus portos, pelo menos desde o século XVIII (MOREL, 2002: 306).

Como o Brasil colonial era uma sociedade marcada pelo baixo letramento e pelo controle sobre os papéis impressos, era natural que a circulação de palavras - às vezes impressas ou mormente faladas e manuscritas - ocorresse de formas variadas: manuscritos, correspondências particulares, papéis e folhas avulsas pregadas nas paredes e muros espalhados pela cidade ou que circulavam de mão em mão (MOREL, 2013: 28). Assim, não é de se estranhar que uma intensa oralidade marcasse a cultura do Brasil nos três primeiros séculos de colonização: tratava-se de uma sociedade em que a palavra impressa era vítima da censura, as casas tipográficas eram proibidas, a maior parte da população brasileira era constituía por analfabetos - brancos e escravos - e o sistema de instrução pública era extremamente precário $^{4}$. O Rio de Janeiro, por exemplo, praticamente não contava com instituições de ensino, com exceção de três colégios religioso (os seminários de São José, de São Joaquim e o da Lapa) e uns poucos professores particulares contratados para ensinar no interior das casas.

Principalmente a partir de 1821, quando foi decretada a liberdade da palavra impressa no Brasil, proliferaram as tipografias ${ }^{5}$ e, com elas, os folhetos e os periódicos (BARBOSA, 2010: 40). No decorrer do século XIX também houve grande aumento das

\footnotetext{
${ }^{4}$ Como aponta Oliveira Lima, “As condições da instrução pública no Brasil colonial dos começos do século XIX eram reconhecidamente deficientes: pode mesmo dizer-se que eram no geral quase nulas [...]" (1996: 159).

${ }^{5}$ Neste ano, surgem duas tipografias no Rio de Janeiro: a Nova Tipografia e a de Moreira e Garcez. No ano seguinte, 1822, instalaram-se mais quatro: a de Silva Porto e Cia., propriedade de Felizardo Joaquim da Silva Morais e Manuel Joaquim da Silva Porto; a de Santos e Sousa; a do Diário do Rio de Janeiro, de Zeferino Vito de Meireles; e a de Torres e Costa, cujos proprietários eram Inocêncio Francisco Torres e Vicente Justiniano da Costa (SODRÉ, 1999: 36).
} 
instituições e espaços de apoio às letras, às ciências e à cultura: livrarias, bibliotecas, gabinetes de leitura, sociedades e academias artísticas, literárias e científicas, colégios regulares e técnicos, seminários, faculdades (inicialmente as de Direito e Medicina), teatros, entre uma série de outros estabelecimentos que auxiliaram, ainda que lentamente, na transformação de uma sociedade extremamente oralizada para uma sociedade cada vez mais letrada, em que a palavra impressa conquistava mais espaço.

Até o desembarque de D. João, o Rio de Janeiro era uma cidade relativamente acanhada, com raras atividades intelectuais (FRANÇA, 2002: 554). Os indivíduos letrados eram poucos e a circulação de seus escritos bastante restrita, sendo veiculada quase sempre em forma de manuscritos (FRANÇA, 1999: 101). Uma anedota publicada no jornal A Grinalda, em 3 de setembro de 1848, ilustra muito bem o que era o mundo letrado no Rio de Janeiro, mesmo já em meados do século XIX:

Um sujeito tendo recebido uma carta de sua família pediu a um seu conhecido o favor de a ler; este, fingindo fazê-lo, de vez em quando interrompia a falsa leitura, dizendo: chore, chore senhor F...; o outro perguntava-lhe pelo que, se havia morrido alguma pessoa de sua família, ou se tinha acontecido alguma desgraça... chore, chore, senhor F... pela desgraça de Vm. não saber ler... nem eu (A GRINALDA, 1848: 92. Grifos no original).

O desembarque da corte no Brasil deu início a novos tempos para cultura letrada, marcando o surgimento dos primeiros consumidores regulares de arte e literatura, momento em que começou a se organizar, pela primeira vez, uma "vida intelectual" no Brasil (LUSTOSA, 2006: 275). Com a Impressão Régia e as demais tipografias fundadas depois de decretada a liberdade de imprensa, percebe-se que, por mais limitada que ainda fosse a "vida intelectual" durante as primeiras décadas do século XIX, a cidade passou a contar com a proliferação de periódicos e livros, assim como com um público receptivo aos impressos e, com isso, às ideias e tendências da época que por eles circulavam (ALGRANTI, 2004: 161).

Por mais que se possa imaginar um público letrado ainda bastante restrito, mesmo entre a camada branca e abastada da população, o que limitaria a circulação das ideias veiculadas nos impressos, há de se levar em conta que, ainda que o texto escrito tenha recebido bom impulso, não substituiu ou passou a predominar imediatamente sobre as formas oralizadas de transmissão cultural características da Colônia: os mundos 
manuscrito e impresso se misturavam ao mundo oral (BARBOSA, 2010: 48). Ou seja, mesmo com o desenvolvimento da imprensa durante as primeiras décadas do Oitocentos, não teria sido possível abandonar abruptamente séculos de transmissão cultural por meio de práticas orais, mesmo porque não seriam encontrados leitores suficientes que garantissem a circulação dos livros, jornais e revistas (PINA, 2002: 43). Os impressos, nesse sentido, ainda se espalhavam pelo Rio de Janeiro por meio das práticas da oralidade. Em uma sociedade com alto índice de analfabetismo, muito do que era veiculado nos jornais chegava à população em geral pelas leituras coletivas realizadas em pontos espalhados pela cidade (LUSTOSA, 2004: 64). Como afirma Marialva Barbosa, "numa sociedade oralizada por excelência, as letras impressas sempre foram mais ouvidas do que lidas" (2010: 21).

Em vista do baixo letramento, escritores e redatores, por meio das páginas dos periódicos fluminenses, foram assíduos defensores da ideia de ampliar a instrução do povo. Já no Correio Braziliense, considerado o primeiro periódico brasileiro, Hipólito da Costa alertava para "a necessidade que há de espalhar instrução útil no Brasil” (1819: $318)$.

A preocupação com a instrução pública foi tema recorrente nos jornais do século XIX. O gosto pelas letras devia-se ao fato de que o "homem sem instrução, oculto nas trevas da ignorância, esse gérmen atrasador do progresso, é qual diamante bruto, é um ente inútil à sociedade" (A NOVA MINERVA, 1846: 127). Por esta razão deveria instruirse, pois a educação do indivíduo acarretaria no melhoramento da sociedade:

A instrução o torna interessante a si e à sua pátria, ela purifica seu espírito, abranda os seus costumes, afasta-o dos princípios de vício, e aponta-lhe a brilhante vereda da virtude, tira-lhe a venda do erro e dá-lhe os olhos da verdade! [...] Ela constitui portanto o principal elemento da civilização, e por conseguinte o da prosperidade de uma nação, como pomposo exemplo nos patenteia a Alemanha, a França e a Inglaterra. Em vista pois de tão irrefragáveis considerações deve a instrução sobre tudo merecer a mais séria atenção de um governo desvelado em promover o bem do seu Estado ( $A$ NOVA MINERVA, 1846: 127). 
O nascimento da imprensa brasileira caracterizou-se pela estreita vinculação com a educação e instrução da população. ${ }^{6}$ Nesse contexto, inicialmente, a instrução associava-se ao esclarecimento político e, em consequência dele, à liberdade e prosperidade dos povos. A associação entre instrução, política e liberdade se fez presente nos periódicos no decorrer de praticamente todo o século XIX, como pode ser visto, em 1865, no Jornal das Famílias: "a ignorância das massas é o primeiro auxiliar do despotismo: um povo sem educação não compreende nem merece a liberdade" (ZALUAR, n. 11, tomo III, novembro de 1865: 340). Nos periódicos, era comum a seguinte afirmação:

Não há melhor povo para se governar do que aquele que for regularmente instruído [...]; quanto mais instruído é um povo, mais elemento de ordem existe entre ele, mais dócil se torna, e a convicção é o instrumento mais forte para se fazer as massas entrarem na órbita da moral e dos bons costumes.

[...] Venha, pois, a instrução. Derrame-se por onde for possível esse orvalho civilizador da humanidade, porque é essa a fonte de todo o progresso ( $A L B U M$ LITTERARIO, 1861: 2).

Um povo instruído era mais fácil de ser governado, pois estaria em contato com os preceitos políticos, morais e sociais mais elucidativos. Como afirma o periódico Annaes Brasilienses de Medicina, em 1865, era preciso "ser na realidade cego para não ver que o futuro das nações depende do grau de instrução a que chegarem". Nesse sentido, continua o periódico, “um povo esclarecido, pelo contrário, será logo um povo livre e saberá conservar sua liberdade, porque saberá fazer bom uso dela" (LAVELEYE, 1865: 339-340, grifo no original). De acordo com a ampla gama de redatores e escritores que publicaram periódicos durante o século XIX, a instrução era considerada um mecanismo fundamental para se incutir novas ideias políticas, o que resultaria no abandono do mundo da ignorância em direção ao mundo da racionalidade, do esclarecimento e, no limite, da liberdade. Como destaca o Acajá, a imprensa tem "sido sempre considerada como a primeira necessidade dos povos livres e muitas vezes a salvaguarda dos seus direitos" (JAMI, 1860: 3).

\footnotetext{
${ }^{6}$ Educação e instrução não eram tidas como sinônimos pela imprensa oitocentista. Diziam respeito a duas coisas diferentes: A "educação" associava-se mais intimamente aos costumes e preceitos morais que deviam ser ensinados à população, enquanto a "instrução" referia-se, sobretudo, ao saber e aos conhecimentos - técnicos, filosóficos, políticos, etc. - que deveriam ser veiculados nos periódicos.
} 
A instrução e o saber adquiriram, assim, um sentido social e político. Ao letrado cabia a obrigação de informar o público sobre os mais importantes acontecimentos políticos da época, ou seja, o jornalista deveria, com base nesse propósito, defender suas ideias e posicionamentos sobre os assuntos políticos, procurando, com isso, influenciar o público leitor (NEVES, 2002: 475). Nos primeiros anos de liberdade de imprensa, esta passou a ser vista como instrumento de difusão particularmente de ideias políticas: por meio dela, iniciava-se a consolidação de uma cultura política ${ }^{7}$ no Brasil, acompanhada pela formação de um espaço público dentro da abrangente esfera privada da sociedade civil, em que se manifestaria a opinião pública ${ }^{8}$.

É na formação de um espaço público de base crítica que os jornais, panfletos e demais folhas deram o tom da nascente imprensa brasileira. Como aponta Lúcia Maria Bastos Pereira das Neves, “as discussões sobre o projeto político a ser instituído no império trouxeram à tona rivalidades e visões de mundo diferentes entre os membros do grupo letrado" (NEVES, 1999: 19). Consequentemente, teve início a construção da nação marcada, na expressão de Isabel Lustosa, pelas guerras de opiniões entre os jornalistas (Cf. LUSTOSA, 2000). Se por um lado tais profissionais confrontavam diferentes projetos políticos sobre o que deveria ser a nação brasileira ${ }^{9}$, de outro, disputavam a conquista da opinião pública, a qual atuaria como mecanismo de legitimação do projeto político defendido e, no limite, de legitimação da disputa e tomada do poder (BASILE, 2006: 90). Tratava-se de um período em que "se debatem os partidos políticos e onde se jogam os vaivéns das revoluções políticas”, como destaca a Chronica Litteraria, em 1848 (CHRONICA LITTERARIA, 1848: 200). Em meio a diversos e divergentes interesses e concepções, os homens da imprensa procuraram formar um cidadão apto à participação

\footnotetext{
7 Ao buscar compreender a cultura política da época da Independência, na obra Corcundas $e$ constitucionais: a cultura política da Independência (1820-1822), a historiadora Lúcia Maria Bastos Pereira das Neves procurou analisar e identificar o vocabulário e as práticas particulares por meio das quais as elites política e intelectual luso-brasileiras deram significado às suas atitudes e interpretaram a realidade que as rodeavam. Tal cultura política seria marcada pelas ideias ilustradas do século XVIII e, mais notadamente, por uma transformação do ideário em que predominava a integração do império lusobrasileiro, em um ideário formado pelos desdobramentos da Revolução de 1820, em que se ressaltava a ideologia separatista (Cf. NEVES, 2003).

${ }^{8}$ De acordo com Marco Morel e Mariana Monteiro de Barros, "considera-se, em geral, que opinião pública remete a uma expressão que desempenhou papel de destaque na constituição dos espaços públicos e de uma nova legitimidade nas sociedades ocidentais a partir de meados do século XVIII. Essa visão percebia no nascimento da opinião um processo pelo qual se desenvolvia uma consciência política no âmbito da esfera pública. [...] Ou seja, a opinião com peso para influir nos negócios públicos, ultrapassando os limites do julgamento privado" (MOREL \& BARROS, 2003: 22).

${ }^{9}$ Como apresenta Marcello Basile, grosso modo existiriam ao menos três projetos políticos para o Brasil representados por três diferentes grupos, cuja disputa intensificou-se durante a Regência: os moderados, os exaltados e os caramurus. Sobre cada um desses projetos e grupos políticos, ver: BASILE, 2008: 222.
} 
política. A polêmica e a tentativa de influenciar a opinião pública (SILVA, 2008: 380) foram as principais armas desses homens de letras. Segundo Marcello Basile, nesse período inicial da imprensa.

A política ultrapassa o tradicional espaço dos círculos palacianos e das instituições representativas e ganha dimensão efetivamente pública. $\mathrm{O}$ discurso político assume papel de destaque em torno do qual se travavam as disputas entre as facções, que buscavam o controle da palavra para legitimarem seus projetos e ações.

[...] Para os pretensos formadores de opinião, fazia-se necessário, portanto, orientar, dirigir e, se possível, controlar essa heterogênea massa ativa, que mal se iniciava nos novos princípios políticos e dava então seus primeiros passos na vida pública. Era preciso educar os indivíduos para a participação política, formar o verdadeiro cidadão, conhecedor de seus direitos. Principal instrumento de ação política no seio do espaço público, a imprensa exercia, assim, uma autêntica pedagogia política do cidadão, divulgando - em versão vulgarizada, adaptada aos seus fins doutrinários e ao público ao qual se dirigia - os termos desse vocabulário político (2008: 207-208. Grifo no original).

Os jornais no Rio de Janeiro, geralmente, mantinham a tradição da imprensa europeia do século XVIII, exercendo o chamado jornalismo de opinião, que colocou em cena a figura do homem público, que, até então, ainda não era encontrada no Brasil. Considerado portador de uma missão ao mesmo tempo política e pedagógica, este novo homem público era uma espécie de escritor patriota, capaz de difundir ideias e incitar debates (MOREL; BARROS, 2003: 15): sua intenção pedagógica vislumbrava preparar seus leitores para a nova realidade política almejada. Assim, os jornais publicados depois da lei que decretou a liberdade de imprensa, em 1821, tinham como propósito preparar o povo para o novo regime político que se inaugurava. Os homens empenhados nessa tarefa confiaram nas virtudes do saber e conferiram à educação a primazia de alavancar a transformação da sociedade (LUSTOSA, 2006: 262). Os periódicos, nesse sentido, eram considerados instrumentos de educação da população e de formação da opinião pública (SILVA, 2008: 391).

Até a Independência, a tônica dos debates nos jornais, que quase sempre surgiam na mesma velocidade que desapareciam, era a pressão impingida pela metrópole e a manutenção ou não de um império luso-brasileiro. A partir de 1822, no entanto, as 
discussões políticas estampadas nas páginas dos jornais passaram a ter como tema a organização da nova nação em construção. ${ }^{10}$ Tendo os leitores/ouvintes como principais interlocutores, a imprensa periódica assumiu o papel de colocar em pauta as discussões sobre o futuro do Brasil, com o objetivo de contribuir para o adiantamento $^{11}$ do país.

Durante as décadas de 1820 e 1830, os jornais e, sobretudo, os pasquins moldaram-se em torno da política, alimentados pelas disputas partidárias entre os diversos grupos e projetos políticos desenvolvidos para a jovem nação que se constituía. Como aponta Hélio Vianna, tratava-se de uma “época em que a preocupação política do Império a organizar-se naturalmente superava todas as outras" (VIANNA, 1945: 97). Nesses primeiros anos, as discussões políticas predominavam na cena pública e eram alimentadas por uma crescente circulação de periódicos, que se constituíram como instrumentos privilegiados de discussão das ideias políticas.

Entre o início da liberdade de imprensa, em 1821, e o final do período regencial, em 1841, o Brasil vivenciou a fase da discussão e dos debates políticos travados entre os diversos partidos em torno de seus projetos políticos para o país, em um cenário recheado por agitações, insultos, desqualificações, difamações pessoais, perseguições, prisões, deportações e atentados. O jornalismo vivia um momento no qual o ataque pessoal passou a ser o centro da sua produção textual, com ofensas e agressões explícitas à idoneidade das pessoas, que se tornavam, muitas vezes, e ao mesmo tempo, vítimas e autoras de chacotas, xingamentos e ofensas pessoais (BARBOSA, 2010: 52). Assim, o jornalismo politicamente militante e agitador, marcado por palavras vulgares, fez do ataque pessoal aos adversários um mecanismo de defesa das ideias políticas. Entre os redatores de destaque estavam Francisco Vieira Goulart (Gazeta do Rio de Janeiro/O Bem da Ordem), Januário da Cunha Barbosa (Revérbero Constitucional Fluminense), Joaquim Gonçalves Ledo (Revérbero Constitucional Fluminense), José da Silva Lisboa (Conciliador do

\footnotetext{
${ }^{10}$ De acordo com Lúcia Maria Bastos Pereira das Neves, "a oposição entre despotismo, enquanto símbolo do passado que se pretendia regenerar, e liberalismo-constitucionalismo, enquanto imagem do futuro que se pretendia construir, traduziu fundamentalmente o ideário político de 1820 a 1823 , com a manifestação de novas atitudes e práticas culturais. [...] A partir de finais de 1821, os jornais publicados no Rio de Janeiro aderiram, em sua maioria, à ideologia separatista, apoiando a ação do príncipe regente d. Pedro. No ano seguinte, modificou-se o teor das publicações, com a multiplicação dos folhetos políticos contrários às Cortes de Lisboa e às atitudes de alguns membros da elite portuguesa. Ao mesmo tempo, os brasileiros começavam a arrancar o tope português, 'trocando o azul e branco pelo verde e amarelo, que significa fertilidade e riqueza'. O sonho de um império luso-brasileiro se desfizera. Doravante, era o império do Brasil que cabia construir, tendo, porém, à testa aquela mesma elite política e intelectual que adequara, ao longo de 1821-1822, as ideias-chave da cultura política portuguesa aos interesses brasileiros" (NEVES, 2003:53).

${ }^{11}$ Para o uso do conceito no período ver, por exemplo, O BEIJA-FLOR (1830: 104).
} 
Reino Unido/Sabatina Familiar), Luís Augusto May (A Malagueta), Manuel Ferreira de Araújo Guimarães (O Patriota/O Espelho), João Soares Lisboa (Correio do Rio de Janeiro), Luís Moutinho Lima Alves e Silva (O Papagaio) Manuel Inácio Ramos Zuzarte (O Macaco Brasileiro), Evaristo da Veiga (A Aurora Fluminense), Antônio Borges da Fonseca ( $O$ Repúblico) e os irmãos Andrada ( $O$ Tamoyo). Como lembra o jornal $A$ Sciencia, em 1848, estes homens marcavam presença "no domínio da polêmica, esta guerra moderna, concentrada nas colunas dos jornais, e não menos séria, não menos fecunda em resultados que as lutas armadas" (MURE, 1848: 188).

A guerra de opiniões, entretanto, com suas disputas partidárias e, sobretudo, os insultos impressos, acabou por afastar a nascente imprensa política brasileira de sua proposta pedagógica originária. Como aponta Isabel Lustosa, “os jornalistas iam se dando conta das imensas possibilidades do jornal para a propaganda política. Possibilidades que o distanciavam cada vez mais do papel educativo inicialmente proposto" (LUSTOSA, 2004: 58). Com o fim da censura, a imprensa passou a ser uma espécie de mola propulsora para o ingresso na vida política: ao invés de instruir, o jornalismo tornou-se vitrine política do jornalista, construída por insultos e difamações aos adversários. Ainda segundo a historiadora, por mais que esses periódicos não tenham deixado de cumprir, ao menos em parte, a tarefa de instruir e educar a população fluminense,

[...] a maior parte dos jornais publicados continha mais injúrias pessoais e impropérios do que informação ou discussões instrutivas sobre princípios políticos.

[...] Exemplar disso será a participação em pasquins ordinários dos outrora idealistas Ledo e Januário, rompidos não por conta de suas ideias, mas por conveniências ditadas pelo oportunismo político que marcaria o final de suas carreiras. Os jornais que escreveriam já não apareciam mais sob a égide dos bons ensinamentos; vinham à luz com o objetivo claro de desmoralizar, destruir o adversário (LUSTOSA, 2000: 419-420).

Em abril de 1844, quando a imprensa política já vinha declinando e perdendo espaço no Rio de Janeiro, o periódico Gazeta Universal fez uma interessante reflexão acerca do jornalismo praticado entre os anos de1821 e 1841:

- É a imprensa política a que entre nós deveria de ter contribuído grandemente para a ilustração das classes inferiores e, em geral, para o melhoramento da 
vida moral e material do povo da pátria; [...] Ela é que prevalecendo na alteza de sua posição social, havia de ter por amplíssimo dever o aprimorar desvelada o espírito do povo, cujo mestre tem sido e é; [...] Mas, em verdade, mal se tem por vez o adstringido a capitular os negócios públicos e as opiniões dominantes; e daqui abusado e baixado desgraçadissimamente a eco dos bandos, a crônica dos escândalos e melhor dos erros e crimes dos caudilhos deles!

E se volvemos os olhos para estes milhares, ou antes milhões de folhas avulsas, que há 15 anos tem alagado da catadupa revolucionária toda esta nossa terra, aflige o ver com quantas futilidades, sem verdades, sem juízos, e fraudes, e torpezas, e misérias, se tem iludido frequentemente a curiosidade, a boa-fé, a confiança do povo: para se lhe dar às braçadas alimento sórdido e empeçonhado ao espírito.

- Luta de parcialidade individuais, luta enfurecida, violenta e estéril, da qual se pode tanto dizer aí dos vencidos, como aí dos vencedores; luta em que como em duelo de morte mais se trata da ofensa que da defensa, em que o ódio e vícios do coração falam mais alto que as conviçcões do entendimento; tal luta sempre travada e mortífera esforça os escritores políticos no Brasil (GAZETA UNIVERSAL, 1844: 1. Grifos no original).

Para o redator, por mais que a imprensa política tenha contribuído para a instrução do povo, ao ampliar o número de leitores, ouvintes, escritores e redatores, bem como para o esclarecimento político e para os debates em torno dos diversos projetos para o Brasil - levando à população as discussões sobre o futuro do país - a guerra entre os jornalistas parece ter afastado do centro da discussão o que era considerado seu grande propósito inicial: atuar como instrumento pedagógico de educação e esclarecimento da população. Ainda assim, desde o surgimento da imprensa já se esboçava o papel que seria reservado ao homem de letras durante o século XIX: o do intelectual como mentor da sociedade, dedicado à aplicação prática das ideias (SILVA, 2006: 378). O modelo de jornalismo mais pedagógico, em que o letrado assumiu para si a tarefa de educar a população, começou a consolidar-se a partir da década de 1840, influenciado pelo golpe da maioridade. Com uma maior estabilidade na política, a literatura e as ciências passaram a ganhar maior destaque nas folhas impressas, assumindo a dianteira do projeto pedagógico almejado pelos letrados por meio da imprensa. "É essa a especialidade do Espelho Fluminense: nada de políticas, nada de diplomacias" (ESPELHO 
FLUMINENSE, 1843: 1), assevera um dos periódicos do início dessa nova fase. A partir de então, a imprensa desvinculou-se do caráter violento e difamador de seus primeiros anos.

Em suma, houve uma estreita vinculação entre a imprensa e um projeto pedagógico na sociedade brasileira oitocentista. Iniciada com o jornalismo político, a imprensa como veículo de instrução da população consolidou-se apenas com a proliferação de publicações mais literárias. Por mais que esse afã pedagógico possa ser encontrado desde a fundação do Correio Braziliense, em 1808, os anos compreendidos entre 1841 e $1870^{12}$ marcam o auge desse processo educacional: foi então que os literatos se consolidaram como os principais colaboradores da imprensa periódica, proliferaram os títulos publicados com ênfase na atividade literária e científica e os debates de cunho político cederam espaço às belas letras, consideradas instrumentos fundamentais de educação e civilização.

Em setembro de 1854, a Marmota Fluminense ressalta sua perspectiva literária afirmando ser um jornal "alheio às discussões políticas, às ridículas personalidades, às intrigas particulares, às travessuras dos partidos" (MARMOTA FLUMINENSE, 1854: 1). A partir de então, nasciam jornais e revistas mais duradouros, de caráter literário, que se tornavam ferramentas de aperfeiçoamento do homem e da sociedade. Este propósito estava em consonância com a Europa que, desde o século XVIII, reconhecia as belas letras como instrumentos do progresso e da civilização. Daí, por exemplo, a defesa da literatura nas páginas do periódico O Cruzeiro do Sul, em 1849:

[...] a literatura é a expressão da sociedade, isto é, a expressão do estado de suas opiniões e costumes e de suas ideias dominantes; e como do maior ou menor, e do mais ou menos verdadeiro que é o pensamento depende a perfeição intelectual e moral do homem, e, por consequência, da sociedade, é evidente que a todo o país que pretende marchar pela senda da cultura convém necessariamente o cultivo da literatura (O CRUZEIRO DO SUL, 1849: 5).

\footnotetext{
${ }^{12}$ Como afirma Nelson Werneck Sodré, os periódicos literários proliferaram mais intensamente até o início da década de 1870, quando, com o fim da Guerra do Paraguai, acirraram-se as disputas partidárias, intensificando os debates políticos nas páginas dos jornais. Como diz o autor, "Ao fim da década de sessenta, com a guerra terminada, tudo indica o início de fase nova, com reformas que se impõem e não podem ser proteladas; a luta política se acirra; a imprensa retoma o fio de sua história, interrompido com a Maioridade. Vai começar a agitação" (SODRÉ, 1999: 200-201).
} 


\section{Fontes}

A GRINALDA: jornal dos domingos (1848), n. 6, vol. 1, 3 de setembro.

A NOVA MINERVA: periódico dedicado as sciencias, artes, litteratura e costumes (1846), n. 32, tomo 2, julho.

ALBUM LITTERARIO: periódico instructivo e recreativo (1861), n. 15, ano 2, 15 de março.

BRASIL (1891). Coleçção das leis do Brazil de 1808. Rio de Janeiro: Imprensa Nacional.

CORREIO Mercantil, e Instrutivo, Político, Universal, Rio de Janeiro (1863), n. 74, 16 de março.

CHRONICA LITTERARIA: jornal de instrução e recreio (1848), n. 25, vol. 1, série 1, 18 de junho.

COSTA, Hipólito José da. Imprensa no Brasil. Correio Braziliense ou Armazem Literario, vol. 22, n. 130, março de 1819, pp. 315-319.

ESPELHO FLUMINENSE ou novo gabinete de leitura, modas, poesias, charadas, etc. (1843), n. 1, 1 de janeiro.

GAZETA UNIVERSAL: instructiva, politica e comercial (1844), n. 1, ano 1, 28 de abril.

JAMI (1860). Saudação ao Acajá. Acajá: jornal de instrução e recreio, n. 1, ano 1, 15 de novembro, pp. 2-3.

LAVELEYE, Emile (1865). Instrução do povo no século XIX. Annaes Brasilienses de Medicina, n. 7, tomo 17, dezembro, pp. 338-342.

MARMOTA FLUMINENSE: jornal de modas e variedades, n. 503, setembro de 1854.

MURE, Benoît Jules (1848). Minhas despedidas. A Sciencia: revista sintética dos conhecimentos, n. 15, vol. 2, 29 de abril, pp. 187-189.

O BEIJA-FLOR: annaes brasileiros de sciencia, politica, litteratura (1830), n. 4.

O CRUZEIRO DO SUL: periódico hebdomanário de instrução e recreio (1849), n. 1, vol. 1,7 de julho.

ZALUAR, Augusto Emílio (1865). A Providência. Jornal das Famílias, tomo III, n. 11, novembro, pp. 339-345.

\section{Referências bibliográficas}

ALGRANTI, Leila Mezan (2004). Livros de devoção, atos de censura: ensaios de história do livro e da leitura na América portuguesa (1750-1821). São Paulo: Hucitec/Fapesp.

BAHIA, Benedito Juarez (2009). História, jornal e técnica: história da imprensa brasileira. Rio de Janeiro: Mauad X.

BARBOSA, Marialva (2010). História cultural da imprensa: Brasil, 1800-1900. Rio de Janeiro, Mauad X.

BASILE, Marcello (2008). Linguagens, pedagogia política e cidadania: Rio de Janeiro, cerca de 1830. In: RIBEIRO, Gladys Sabina (Org.). Brasileiros e cidadãos: modernidade política 1822-1930. São Paulo: Alameda, pp. 207-224.

(2006). Projetos de Brasil e construção nacional na imprensa fluminense (18311835). In: NEVES, Lúcia Maria Bastos Pereira das; MOREL, Marco; FERREIRA, Tania Maria Bessone da Cruz. História e imprensa: representações culturais e práticas de poder. Rio de Janeiro: DP\&A/Faperj, pp. 60-93. 
BRAGANÇA, Aníbal (2005). António Isidoro da Fonseca: um precursor na história do livro brasileiro. In: MELO, José Marques de (Org.). Imprensa brasileira: personagens que fizeram história. vol. 4. São Paulo: Universidade Metodista de São Paulo/Imprensa Oficial do Estado de São Paulo, pp. 41-52.

CABRAL, Alfredo do Valle (1881). Annaes da Imprensa Nacional do Rio de Janeiro de 1808 a 1822. Rio de Janeiro: Typographia Nacional.

CAMARGO, Ana Maria de Almeida; MORAES, Rubens Borba de (Orgs.). Bibliografia da Impressão Régia. São Paulo: Edusp/Kosmos, 1993, 2v.

FRANÇA, Jean Marcel Carvalho (2002). A construção de um público. In: DINES, Alberto; LUSTOSA, Isabel. Hipólito José da Costa e o Correio Braziliense. São Paulo: Imprensa Oficial do Estado/Brasília, DF: Correio Braziliense, pp. 553-604. Literatura e sociedade no Rio de Janeiro oitocentista. Lisboa: Imprensa Oficial/Casa da Moeda, 1999.

LIMA, Oliveira (1996). Dom João VI no Brasil. Rio de Janeiro: Topbooks.

LUSTOSA, Isabel (2006). Cairu, panfletário: contra a facção gálica e em defesa do trono e do altar. In: NEVES, Lúcia Maria Bastos Pereira das; MOREL, Marco; FERREIRA, Tania Maria Bessone da Cruz. História e imprensa: representações culturais e práticas de poder. Rio de Janeiro: DP\&A/Faperj, pp. 275-295.

(2000). Insultos impressos: a guerra dos jornalistas na Independência (18211823). São Paulo: Companhia das Letras.

(2004). O nascimento da imprensa brasileira. Rio de Janeiro: Jorge Zahar Ed..

MARTINS, Wilson (1957). A palavra escrita: história do livro, da imprensa e da biblioteca, com um capítulo referente à propriedade literária e, em apêndice, as convenções de Berna, de Washington e Universal, sobre os direitos autorais. São Paulo: Editora Anhembi Limitada.

MINDLIN, José (2010). Impressão Régia: seu significado e suas realizações. In: BRAGANÇA, Aníbal; ABREU, Márcia (Orgs.). Impresso no Brasil: dois séculos de livros brasileiros. São Paulo: Editora Unesp, pp. 19-21.

MOREL, Marco (2002). Entre estrela e satélite. In: DINES, Alberto; LUSTOSA, Isabel. Hipólito José da Costa e o Correio Braziliense. São Paulo: Imprensa Oficial do Estado/Brasília, DF: Correio Braziliense, pp. 269-320.

(2013). Os primeiros passos da palavra impressa. In: MARTINS, Ana Luiza; DE LUCA, Tania Regina (Orgs.). História da imprensa no Brasil. São Paulo: Contexto, pp. 23-43.

\& BARROS, Mariana Monteiro de (2003). Palavra, imagem e poder: o surgimento da imprensa no Brasil do século XIX. Rio de Janeiro: DP\&A.

NEVES, Lúcia Maria Bastos Pereira das (2003). Corcundas e constitucionais: a cultura política da Independência (1820-1822). Rio de Janeiro: Revan/Faperj.

(1999). Intelectuais brasileiros nos Oitocentos: a constituição de uma 'família' sob a proteção do poder imperial (1821-1838). In: PRADO, Maria Emília (Org.). $O$ Estado como vocação: ideias e práticas políticas no Brasil oitocentista. Rio de Janeiro: Access, pp. 9-32.

(2002). Pensamentos vagos sobre o Império do Brasil. In: DINES, Alberto; LUSTOSA, Isabel. Hipólito José da Costa e o Correio Braziliense. São Paulo: Imprensa Oficial do Estado/Brasília, DF: Correio Braziliense, pp. 469-513.

OLIVEIRA, Paulo Motta (2011). E a imprensa chegou ao Brasil: reflexões sobre livros, invasões e mercados. In: FERREIRA, Tânia Maria Bessone da Cruz et al. D. João VI e o Oitocentismo. Rio de Janeiro: Contra Capa/Faperj, pp. 55-63. 
PINA, Patrícia Kátia da Costa (2002). Literatura e jornalismo no oitocentos brasileiro: estudo das estratégias dos produtores de cultura para a formação e a manutenção de um público consumidor do impresso. Ilhéus, BA: Editus.

SILVA, Ana Rosa Cloclet da (2006). Inventando a nação: intelectuais ilustrados e estadistas luso-brasileiros na crise do Antigo Regime Português (1750-1822). São Paulo: Hucitec/Fapesp.

SILVA, Carolina Paes Barreto da (2008). Direitos, liberdade e cidadania no jornal O Repúblico (1830-1831). In: RIBEIRO, Gladys Sabina (Org.). Brasileiros e cidadãos: modernidade política 1822-1930. São Paulo: Alameda, pp. 379-395.

SODRÉ, Nelson Werneck (1999). História da imprensa no Brasil. Rio de Janeiro: Mauad.

VIANNA, Helio (1945). Contribuição à história da imprensa brasileira (1812-1869). Rio de Janeiro: Imprensa Nacional.

VILLALTA, Luiz Carlos (1997). O que se fala e o que se lê: língua, instrução e leitura. In: NOVAIS, Fernando Antonio (Coord.); SOUZA, Laura de Mello e (Org.). História da vida privada no Brasil: cotidiano e vida privada na América Portuguesa. vol. 1. São Paulo: Companhia das Letras, pp. 331-385

Artigo recebido em 28 de março de 2015.

Aprovado em 10 de junho de 2015. 